\title{
Political Reasoning and the Typology of Arguments in the Context of Political Philosophy
}

\author{
Łukasz Perlikowski \\ Nicolaus Copernicus University in Torun
}

\begin{abstract}
The main purpose of this article is to present the initial phase of the project in the field of argumentation theory and political philosophy. Project concerns studies of different types of rationality in the context of the argumentation. Background consideration is the problem of incommensurability and incompatibility types of rationality in political and ideological disputes. The first step is the establishment of a category of argumentative potential as a criterion for the typology of argument, which will build a map of argumentation, which will provide a starting point for a discussion. Apart from demonstrating the disproportion of discourses, the conclusion of the argument is to prove the local character of rationality.
\end{abstract}

Keywords: typology of argumentation, argumentative potential, political philosophy, New Rhetoric, political reasoning, universal audience, verbalism, Faustian Bargain

\section{Introduction}

What does it exactly mean that given argument is good? Is it good because of its efficiency understood as power of persuading? Or the quality of arguments consists in following the objective truth? That's the first dilemma. The second dilemma is related to the role of argument within the frame of controversy. Namely, is the good argument supposed to resolve the problem and close discussion? Or is good argument the one that opens the discussion and extends the scope of consideration?

In the context of first problem, Artur Schopehauer proposes good solution. In his handbook of argumentation, he claims that it is possible to be right in the meaning of objective truth, but in the struggle of arguments one can fall down without good arguments, rhetorical capabilities, and eristic methods. ${ }^{1}$ To resolve the second problem, we need more comprehensive analysis and this problem will be leitmotiv of our consideration.

The content of this article is part of a bigger theoretical project. It is basically an initial phase, which purpose is to create a map which describes orders of argumentation. This map should be treated like an instrument for further analysis which consists of relations between argumentation and rationalities. The main goal of this article is to present typology of argumentation - map of arguments - and conceptualization of the argumentative potential notion, which is the criterion of our typology.

Łukasz Perlikowski, MA, Faculty of Political Sciences and International Studies, Nicolaus Copernicus University in Torun, Poland; main research field: Political Philosophy, Rationality, and Argumentation Theory. 


\section{The Argumentative Potential}

In the light of our problem, there are two meanings of the concept of good argument. The first type of good argument could be understood as an argument which settles a solution and closes a dispute. The second type is an argument which brings dynamics to discussion and provides a development of controversy; it leads to reinforcement of both standpoints - proponents and opponents. We can see this distinction very clearly in the Daniel Dennett's observation, which is called Faustian bargain:

... if Mephistopheles offered you the following two options, which would you choose? (A) You solve the major philosophical problem of your choice so conclusively that there is nothing left to say (thanks to you, part of the field closes down forever, and you get a footnote in history). (B) You write a book of such tantalizing perplexity and controversy that it stays on the required reading list for centuries to come. ${ }^{2}(2014,411)$

The second meaning of good argument moves out consideration closer to the idea of argumentative potential. The author of "Open Society and Its Enemies" postulates something, which Michał Heller names discussionability of arguments:

I think that here appears an accuracy of Popper's proposal, for the equivalent of falsifiability in the empirical science we can take a discussionability in philosophy - to treat as worthy only these directions in philosophy which are open for discussion. I would like to add from myself, that declaration of willingness is articulated by everyone or almost everyone but we need the real openness for discussion, readiness to accept good arguments from our opponents. Only on account of critical discussion assumed visions can be corrected. ${ }^{3}(2006,95)$

Popper names his position critical rationalism opposed to non-critical rationalism, and he describes it with the following words:

This latter attitude (critical rationalism) with its emphasis upon argument and experience, with its device "I may be wrong and you may be right, and by an effort we may get nearer to the truth", is, as mentioned before, closely akin to the scientific attitude. It is bound up with the idea that everybody is liable to make mistakes, which may be found out by himself, or by others, or by himself with the assistance of the criticism of others. It therefore suggests the idea that nobody should be his own judge, and it suggests the idea of impartiality. (This is closely related to the idea of "scientific objectivity" as analysed in the previous chapter.) Its faith in reason is not only a faith in our own reason, but also-and even more-in that of others. ${ }^{4}(1966,433)$

Critical rationalism is therefore certain argumentative attitude. Moreover, this attitude grants primacy some kind of arguments. The minimal condition is ability to justification but more the wider extent of justification that it has, and the arguments are stronger. Argument should not have any burden which would block it to self-criticism. The ideal example of such an argument would be argument separated from given position. Above condition of good argument consists of criterion which we name argumentative potential.

Pros hen ${ }^{5}$ of argumentative potential is a permanent deliberation, which within our framework is called reflective threshold. This element should be recognized as an argumentation which inclines us toward suspending the decision and participate in mental process. John Dewey has described this process: "The existing impulses are temporarily inhibited. We say: 'Stop and think.' That is tautology. The thinking is stopping and stopping is thinking. That is, the inhibition of an impulse will throw it into the region of idea" $(1976,61)^{6}$ The moment of concerning is a stopping point and then we are turning toward theories and thoughts to achieve a right solution. We can find it in this author's words: 
Deliberation is a rehearsal of action. While it is intellectual, it is not a mere indifferent consideration of objective things. It is not thinking about certain possibilities and results; it is imaging these as actually operative and at work. It is imaginative experimentation... To say it is rehearsal means that it is mental... this deliberation is not mere putting of certain data before us. We project ourselves into this imaginary result. If we can do that, we get a feeling of satisfaction and will be certain to go ahead on that line unless some other obstacle intervenes. ${ }^{7}(1976,60)$

Deliberation is a form of activity which is similar to the main Popper's concept, namely that all human activities rely on struggle with problems in the following order: problem-reflection-solution-new problems derived from this solution.

On this ground we can notice similarity between Popper and Dewey's ideas-evolutionary theory of knowledge/deliberation and in the postulates of reflexive thinking/critical thinking. According to Dewey reflexive thinking,

... means judgement suspended during further inquiry; and suspense is likely to be somewhat painful. As we shall see later, the most important factor in the training of good mental habits consist in acquiring the attitude of suspended conclusion, and in mastering the various method of searching for new materials to corroborate or to refute the first suggestion that occur. To maintain the state of doubt and to carry on systematic and protracted inquiry-these are the essentials of thinking. ${ }^{8}(1910,47)$

In sum, there is a certain type of argumentation which essence is reflection, investigation. If we would separate this piece from the entire process, then we would gain something what we can call argumentation with the highest level of argumentative potential. This construction has an ideal character. Ubiquitous of this kind of argumentation would lead to inhibiting us from deciding in any issues, "Stop and think," "That is tautology." Establishment of this point and this kind of argumentation is a necessary step from the heuristic point of view. It is an example of assertions and conditions of these assertions which have the highest level of argumentative potential. And the category of argumentative potential will prompt to draw the map of argumentation.

\section{Typology of Argumentation}

If we use Popper's and Dewey's postulates and the others mentioned above for our analysis purposes, then typology of argumentation could have a shape of a curve on the graph. On this graph we can find two axes, and there is axis $y$ which shows us a level of openness and reflexiveness, and axis $x$ which presents a development of given types of arguments, which are simetrically devided by so-called reflexive treshold.

Reflexive treshold (which we shall describe and analyze in the following part of article) is a landmark of our graph. It should be recognized as idea of permanent argumentation process where arguments are separated from any point of view. After transgression of this threshold, arguments are changed but still remain within some kind of relations with former arguments - those relations have symmetric character. Points from A to G designate types of argumentation. 


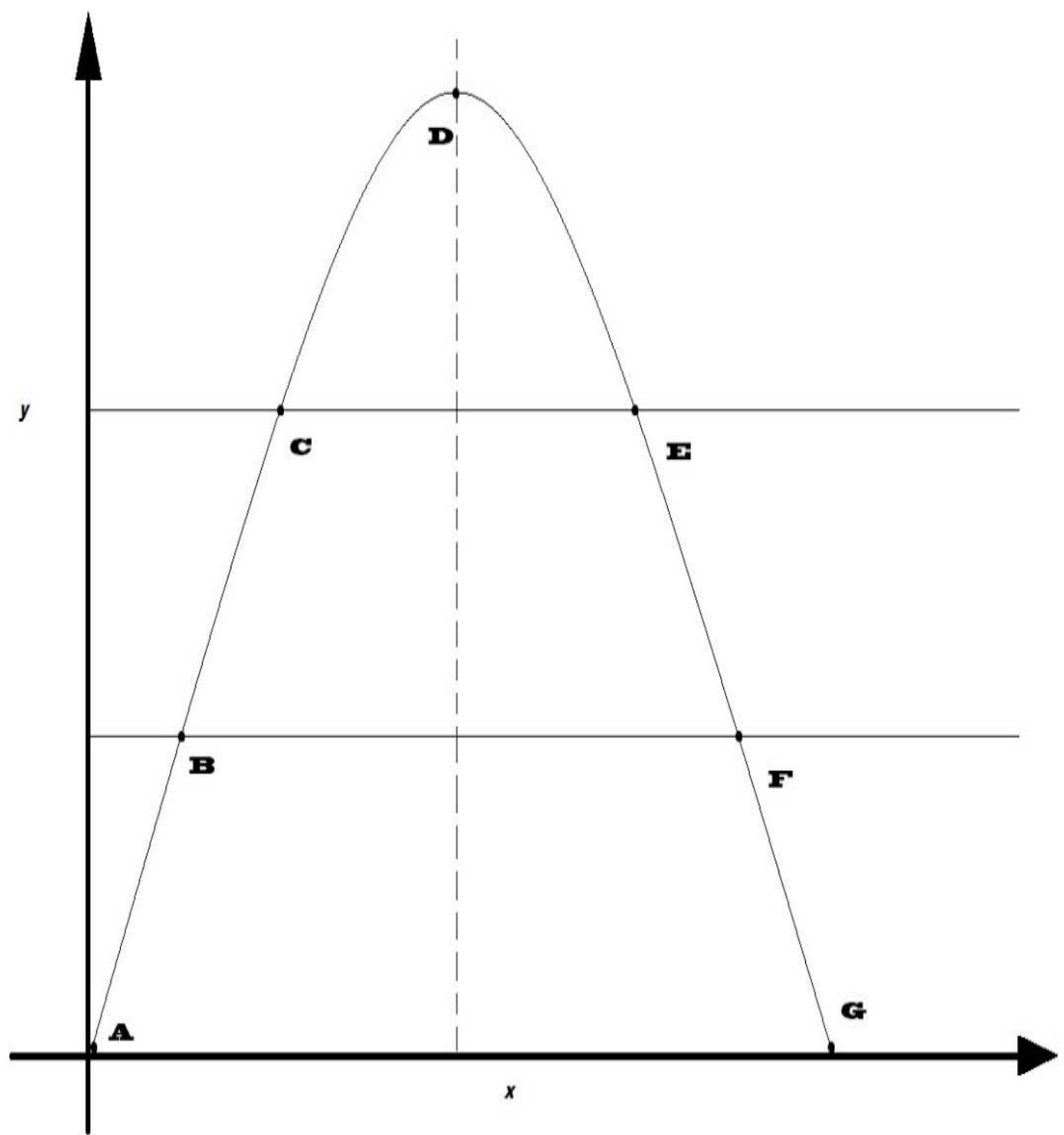

Fig. Typology of argumentation.

Michał Heller writes about similar structure in the following sentence:

I do claim that argumentations occurring in philosophy as well as in sciences, could be sorted by the line and on the left end; left end would be argumentations without hermeneutical component, and on the right end would be argumentations without logical-deductionist component (if such argumentations does not exist, than with minimal logical-deductionist component). The argumentation is closer to the left end than hermeneutical component is smaller; and symetrically: The argumentation is closer to the right end than logical-deductionist component is smaller. Rationalist argumentation would be relatively close to the left end of the line; visionary argumentation would be accordingly close to the right end of the line. It is worth to notice that there is no philosophical argumentation — only if it does not concern trivial assertion-without hermeneutical component. ${ }^{9}$ (93)

To explain, hermeneutical component of this part of argumentation which is responsible for explanation of given vision, enables us to have an internal perspective of argumentation. Logical-deductionist component is the contrary for this - it is an assertion, which is self-defended and has no relations with any vision, but it is related to logical rights. 
The fundamental difference between Heller's approach and our consist in that our typology of argumentation is built on political philosophy ground, where argumentation is strongly focused on persuading and has more or less character of argumentation in the public sphere, while Heller's typology (following Woleński) embraces also argumentation with strictly philosophical and logical character. There we can easily find arguments without hermeneutical component - the main example is formal logic, which in the context of public sphere or art of persuading have a small value in comparison to another instruments of reasoning.

The next step of our consideration is to elaborate a map of argumentation which bases on graph described above. Each points of this graph should be understood as certain model. The purpose of this model is to show a formal condition of arguments functioning. It shall be an evidence for diversity and plurality of such models and leads us to claim that there are much different kinds of rationalities, and within this frame there are arguments origined from different points of view. This way we can avoid problems is related to coherence of given point of view - our assumption is that within the frame of one point of view there can exist arguments from different kinds of rationalities. Typology we propose does not run out of all possibilities of argumentation and moreover it can't embrace all types of rationality.

By the use of criterion, we can indicate the following types of argumentation: (A) non-logical argumentation, (B) emotivistical argumentation, (C) particular audience argumentation, (D) reflexive argumentation, (E) paradigmatic argumentation, (F) relativity argumentation, and (G) logically closed argumentation.

\subsection{Non-logical Arguments (A)}

Those types of arguments are characterized by separation from the category of rationality understood in common meaning. But there is some kind of relation between these arguments and rationality. If we look at this problem from the perspective of the model of rationality, we can say that this is "irrational rationality;" that there are some conditions which determine the shape of assertions and thesis. One of those conditions might be faith. These arguments are articulated without any factor with reasonable origin, but with mystical impulse or as outcome of unconscious errors of reasoning or inconsistency.

In the frame of reasonable investigations, they should be recognized as a wrong path of argumentation and they are signals to retreat. But paradoxically, in some points of view, non-logical arguments have a power and they are higher than such categories as: obviousness, necessity, rationality, or reason.

The primary case of non-logical arguments (A) is so-called performative inconsistency, which John Finnis has shown in example of incorporation the knowledge into the catalogue of basic goods. ${ }^{10}$ This co-founder of New Natural Law Theory develops his argumentation in the following vein. He enumerates examples of basic principles which constitute a rational consideration: (1) the forms of deductive inference are to be used and adhered to in all one's thinking, even though no non-circular proof of their validity is possible (since any proof would employ them); (2) an adequate reason why anything is so rather than otherwise is to be expected, unless one has a reason not to expect such a reason; (3) self-defeating theses are to be abandoned; (4) phenomena are to be regarded as real unless there is some reason to distinguish between appearance and reality; (5) a full description of data is to be preferred to partial descriptions, and an account or explanation of phenomena is not to be accepted if it requires or postulates something inconsistent with the data for which it is supposed to account; (6) a method of interpretation which is successful is to be relied upon in further similar cases until contrary reason appears; (7) theoretical accounts which are simple, predictively successful, and explanatorily 
powerful are to be accepted in preference to other accounts. ${ }^{11}$ On self-evidence of practical principle, which constitutes knowledge as primary good, author has written that these principles of theoretical rationality are undemonstrative; it means that there is no possibility to prove it or to refute, because each evidence assumes them. We should grant them objective status. They are binding regardless of the context of inquiry. Moreover:

But to defy them is to disqualify oneself from the pursuit of knowledge, and to deny them is as straightforwardly unreasonable as anything can be. In all these respects, the principles of theoretical rationality are self-evident. And it is in these respects that we are asserting that the basic practical principle that knowledge is a good to be pursued is self-evident. ${ }^{12}(2011,69)$

We can find the same problem in the Aristotle's legacy:

Hence since these axioms apply to all things qua Being (for this is what is common to them), it is the function of him who studies Being qua Being to investigate them as well. For this reason no one who is pursuing a particular inquiry neither a geometrician nor an arithmetician... Clearly, then it is the function of the philosopher, i.e., the student of the whole of reality in its essential nature, to investigate also the principles of syllogistic reasoning... Now this person is the philosopher, and the most certain principle of all is that about which one cannot be mistaken; for, such a principle must be both the most familiar (for, it is about the unfamiliar that errors are always made), and not based on hypothesis. ${ }^{13}$ (1005a-1005b)

Claims that contradict these principles do simultaneously contradict the essence of inquiry.

Finnis shows a formal dimension of the performative inconsistency, but we can see this clearly also in Steven Lukes' consideration on the relativism-universalism dichotomy. ${ }^{14}$ The main goal of this author is to demonstrate a relevant difference between relativism and pluralism. Relativism is related to the trap of self-refutation. Performative inconsistency consists in identifying given point of view as determined by culture and then this consideration would lead to identifying further point of view as determined by some kind of culture as well. Shortly, theses about culture determinism are themselves determined by the culture.

Finnis gives us an example, which is related to idea of negate ethics as subject worth to participate and as way of life:

It would be irrational to assert that that choice (choice to engage in the activity of pursuing this ethical quest) is not a good and worthwhile choice; for like any other assertion would need justification, and identification of reasons for the assertion would itself be an instance of the very activity asserted to be not worthwhile id either unsupported (and so not worth considering) or it is self-refuting. ${ }^{15}(1983,4-5)$

An intense example of non-logical arguments and performative inconsistency is Lev Shestov's irrational philosophy, which Nicolas Bierdjawiej describes in this way:

L. Shestov frankly was not interested by this problem (problem of a communication from one to another) and he did not write about it, since he was completely absorbed by the relationship of man and God, and not by the relationship of man and man. But his philosophy very acutely posits this problem, and he himself is beset by the problem of philosophy. His contradiction was in this, that he was a philosopher, i.e., a man of thought and knowledge, and he comprehended the tragedy of human existence, the negative apperception. He struggled against the tyranny of reason, against the force of knowledge which banished man out of paradise, yet he struggled upon the territory of that same knowledge, and recoursed to the weaponry of that selfsame reason. ${ }^{16}(2007,8-9)$

Shestov's philosophy seems to base on the contradiction from the beginning. The title of one of his books is Dostoevsky and Nietzsche the Philosophy of Tragedy. ${ }^{17}$ In this book, he tries to develop a theory of existentialism and emphasis the individual which is open for absolute which main trait is supremacy over necessity, obviousness, law of nature, rationality, and morality. Eutyphro's dilemma is solved for gods. 
Author is going to prove this by analyzing extreme points in Frydrich Nietzsche'z and Fyodor Dostoewsky's existence and legacy. He tries to prove, so he employees an evidence and builds a quasi-logical discourse. And this is the best support for thesis that the category of rationality is necessary, even in the rudimentary form.

We should keep in mind that our remark is according to the Heller's analysis in this part where he shows it is impossible to find argumentation with completely lack of logicaly-deductionist element. Evidence for this thesis is performative inconsistency of Shestovian irrationalism mentioned above. For the refutation of logic, author uses quasi-logic means and contradicts himself. Non-logical arguments do not require a justification because they negate every kind of justification. In this case, reason is in lack of reason like in Tertulian credo quia absurdum. Moreover, we should recognize non-logical arguments as some form of solipsism, like Heller shows: "Sentences on vision out of this vision means nothing or have meaning different from the author's intention. Acknowledgement of vision is related to exploration of the meanings" (91). ${ }^{18}$

Other examples of using argumentation A, which cross boundaries of the rational epistemological horizon, which exclude rational justification, and which base on performative inconsistency, are self-refuting arguments. An example from biopolitical debates is Jürgen Habermas's observation on self-instrumentalization of human specie:

But if eugenic manipulation changes the rules of the language game itself, this act can no longer be criticized according to those rules. Therefore, liberal eugenics provokes the question of how to value morality as a whole... No arguments from the moral language game itself can be mustered against a eugenic self-instrumentalization of the human species which changes the very rules of the game. All that remains at the appropriate level of argumentation are morally self-reflective, that is, species-ethical consideration on the organic (and, in their consequences, the mental) presuppositions necessary for the moral self-understanding of s acting persons. However, species-ethical considerations of this kind dispense with the presumptively compelling force of strong moral reasons. ${ }^{19}(2003,92-94)$

If we would like to develop this argument, we could say that protagonists of "eugenic autoinstrumentalization of specie," so for example transhumanists claim that category of human nature is not worth to preserve, and should not be a subject of our concern. But they assess condition of the specie from internal point of view-from the perspective of human specie. This perspective assumes that somewhere exist different kinds of worlds, where we would find different creatures, which could have a completely different moral axiology. Moreover, there could exist none of moral axiology in our meaning. Performative inconsistency consists in self-refuting which transhumanist is done by the following way: If we assume that the parts of human nature are moral arguing, ethical investigations, and rational justification, and that these parts are not worth to protect, then we negate human nature by using rational justification, moral arguing, and ethical investigation. So we try to refute human nature, but by the using of instruments, which are part of the human nature. We can make a paradoxically assertion that this attempt to refute human nature is essential evidence for human nature.

Non-logical arguments that occur in political philosophy discourse have their believers and protagonists, but it is essential to remember that these theses are not actually arguments in the proper meaning. Arguments are related to evidence, arguing, persuading, right, and reasoning. But identification of non-logical argumentation is worth on two dimensions. Firstly, it is identification of certain kind of argument; secondly, we can catch relations between other types of argumentation. We can also uncover errors and show non-logical characters of assertions. We can find emotivistical argumentation (B) on the one level up. 


\subsection{Emotivistical Arguments (B)}

To this group belongs to inter alia moral claims and preferences. They function on the ground which is separated from any category of rationality, but they could establish a start point for moral reasoning and it can be compared to the requirements of rationality. We can find this process in the example of reflexive equilibrium method. It consists on juxtaposing three kinds of elements: moral claims, moral principles, and background theory. ${ }^{20}$ Moral claims without other parts have a low rate of argumentative potential.

Assertions from these types of argumentation have a subjective character, but the subjectivism is narrower category than emotivism. Moral claims are articulated in the spontaneous vein; it is some kind of expression which precedes any moral reasoning or rational investigation. Moreover, these arguments have a psychological basis. We could say that each of emotivism is a subjectivism but not all subjectivisms are emotivism. The reason for which we single this type of argumentation out is that there occur assertions which are using expression instead of justification.

Alasdaire MacIntyre shows that:

In Human reasoning, just as much as in Aristotelian, there is no place for a premise of the form "I want such and such." Why not? It is of course for very different reasons from those adduced by Aristotle. It is on Aristotle's view the case that my taking pleasure or pain in something is never by itself a reason, let alone for good reason, for action, even when I may in fact be moved to action by the prospect of either pleasure or pain. It is only insofar I take it that the achievement of some pleasure or the avoidance of some pain will provide me with some good that I am afforded a reason for action, and then my reason is of the form "Achieving such and such is good for such and such person." (Alasdaire MacIntyre, Whose justice? Which Rationality? University of Notre Dame Press, Notre Dame Indiana, 1988, 305)

On Hume's view, although it is indeed the case that the prospect of pleasure or pain moves me to action, what moves me is the relevant passion - in modern idiom the relevant desire - and not its expression in utterance of the form "I want such and such." I may indeed give expression to my passion by such a type of utterance, but the utterance in and by itself, as I noted earlier, plays no part in generating action. ${ }^{21}$ Let us focus on the construction of emotivistical argumentation ("I want such and such"). It is in essence free utterance which has no meaning in separation from the context of rationality. It is conditioned by psychologic and has a pre-reflexive character. The main purpose of Hume's and Aritotle's considerations (of course in the different style) is in essence searching for background of our activities. They concern motivation and intention of our acts and the place of practice rationality in this context. We are supposed not to recognize emotivism as an approach which excludes a category of rationality but rather as an approach which avoids this category. This difference consists of difference of levels.

Arguments from section B are related to ethical subjectivism and individualism, which Lesław Niebrój depicts:

Psychological dependence of theory seems to be an intellectual trap, which lots of thinkers get in... in the real world subjectivist per se does not articulate any claims on dependence or independence good and evil, but on the its (non)objective status. There could be a lot of version of the ethical subjectivism. Specific (most radical) example of subjectivist can get a shape of radical individualism, but we can also talking about ethical subjectivism of moral communities. ${ }^{22}(2010,174)$

Arguments belonging to group B are just arguments related to individualism. They differ from relativism, because they ignore the category of good and evil, because this kind of arguments cannot reach this level of moral reflection, which is represented by moral principles where the main measure bases on these categories. 
For this kind of consideration, we have to create a wider perspective of rationality what enables us to think about justifications.

Emotivism ceases moral process on the articulation stage. It is rather articulating than arguing, rather producing claims than persuading. The intersubjective factor shall occur on the next level-in the arguments of particular audience.

\subsection{Particular Audience Argumentation (C)}

This conception assumes that there exist particular epistemic communities that have some basic assumption. We cannot ignore these assumptions, if we would like to argue effective and adequate. It determines the quality of communication within these communities. These arguments are strongly bound to tradition, which leads us to the problem of translation between communities.

Helpful theoretical frame for analyzing this argumentation is Chaim Perlaman's idea of particular audience. ${ }^{23}$ He distinguishes three types of audience: (1) individual-it means self-deliberation or internal dialog; it happens when trying to get convenience about something; (2) particular audience-group of individuals which believe in the same values, what makes community and all processes of argumentation must be devoted to common values. Any assertion within this community has to be a part of system and the main trait of this system is coherence. The main possible mistake is so-called petitio principii, which Perelman describes: "Because principle of identity is regard to truth of sentences and not acceptance of assertions has been never negated. Instead, that is obviously, that one who want to convince audience to certain thesis, he cannot assume this thesis a priori" $(1984,158) .{ }^{24}$ Author underlines, what is relevant from the perspective of our consideration, that we are dealing with acceptance of the thesis, and not searching the truth of this thesis; (3) universal audience - it is an abstractive idea which has normative character. It supposed to be used by prudence legislator or by judge. The requirements of universal audience fulfill conditions of rational reasoning regardless of particular factors which could be found in particular audience. We can find particular audiences in believers, communities, association, social groups, local societies, and subcultures.

Interesting theoretical category which concerns this type of argumentation is Wittgenstein's theory of language games which is so-called second Wittgenstien philosophy. The particular audience argumentation (C) is specifically related to paradigmatic argumentation (E).

\subsection{Reflexive Argumentation (D)}

Conception of universal audience is an abstract idea and its main trait is abstracting from any substantial issues. One of the main purposes is to leave the particular audience or burden of other arguments within one point of view. Perelman notices that universal audience is related rather to the process of convincing than to the process of persuading. ${ }^{25}$ Persuading is directly connected to the emotional and psychological sphere, but it is not really valuable from the perspective of universal audience. In the context of our map, we should notice that there is a conspicuous discrepancy between argumentation of universal audience (D) and non-logical argumentation (A), what is proved by the location of these points on the map. Argumentation of universal audience associates reason participants; anything beyond the reason is not value, and should be excluded from rational discourse. ${ }^{26}$ In the non-logical argumentation, it is vice versa-reason is the main enemy.

Another relevant trait of type D argumentation is right supremacy over facts. It means that facts are conditioned by interpretation and process of describing could not be adequate. Hence, the bases of arguing are 
rights and rules. Like authors of New Rhetoric show:

The agreement of a universal audience is thus a mater, not of fact, but of right... Argumentation addressed to a universal audience must convince the reader that the reasons adduced are of a compelling character, that they are self-evident, and posses an absolute and timesless validity, independent of local or historical contingencies. ${ }^{27}$ (32)

Logical rules have an essential meaning here: "Thus, maximally efficacious rhetoric, in the case of a universal audience, is rhetoric employing nothing but logical proof" (32). ${ }^{28}$ But the only formal logic or other conception which has only logical-deductionist component is not the point but the common rules-loci communes—which has power independence from any particular audiences. Moreover, we have to deal with the hypothetical audience: "We expect our judgments to be confirmed by the reactions of others. However, the 'others' to whom we appeal are not just any 'others.' We make our appeal solely to those who have duly 'reflected' on the conduct we approve or disapprove" (32). ${ }^{29}$ Even so, universal audiences stay in some relation to particular audiences: "We believe, then, that audiences are not independent of one another, that particular concrete audiences are capable of validating a concept of the universal audience which characterizes them" $(35) .^{30}$ The main trait of this audience is persuading:

For, certain features of the universal audience will always coincide with the real concrete person: The universal audience will only differ from a particular audience in the measure that the conception held of the universal transcends given particular audiences. Then, too, the reactions of a given audience, even if they are capable of interpretation in psychological, or even political terms are nevertheless very often capable of being explained and justified on grounds that could be accepted by the universal audience, and which make those reactions to some extent rational. ${ }^{31}$ (502)

In this point, we should shed some light on the structure of New Rhetoric. Authors of this conception assume that there are three types of separated audiences, which are set in hierarchic order. It means that individual audience is under particular audience and above this audience we can find universal audience. But in fact, this relation is rather horizontal than vertical. Universal audience is rather nexus between different kinds of audiences than abstract unavailable idea:

This is as true of the different incarnations of the universal audience as it is of particular audiences. At first sight, order does not matter to the universal audience. But the universal audience is no less than other audiences a concrete audience, which changes with time, along with the speaker's conception of it. ${ }^{32}$ (491)

What formulation can we make of audiences, which have come to play a normative role, enabling us to judge on the convincing character of an argument? ... We hasten to add that it is only when the interlocutors in a dialogue and the man debating with himself are regarded as an incarnation of the universal audiences, that they can enjoy the philosophic privilege conferred to reason, by virtue of which argumentation addressed them has often been assimilated to logical discourse. Each speaker's universal audience can, indeed, from an external point of viewpoint, be regarded as a particular audience, but in none the less remains true that, for each speaker at each moment, there exists an audience transcending all others, which cannot easily be forced within the bounds of a particular audience. On the other hand, the interlocutor in a dialogue or the person engaged in deliberation can be considered as a particular audience, with reactions that are known to us, or at least with characteristic we can study. Hence, the primordial importance of the universal audience, as providing a norm for objective argumentation, since the other party to a dialogue and the person deliberating with himself, can never amount to more than floating incarnations of this universal audience. ${ }^{33}$ (31)

Common ground for all audiences is searching for some kind of rationality:

In general a speaker or writer who desires to win the adherence of the universal audience will give up arguments that this audience — as he conceives it — would find inadmissible, even when he is addressing a particular audience. He will deem it almost immoral to resort to an argument which is not, in his own eyes, a rational one. ${ }^{34}$ (483) 
Any considerations on dilemma dichotomy particular-universal are related to problem of skepticism. Universalists are accused of falling into Archimedes point trap and wrong "external perspective." Ronald Dworkin proposes excellent solution for this problem. Let us use his idea for our investigations.

There are two orders that exist within moral philosophy. The first order has substantial character and questions related to it concerning internal dimension of system of ideas; the second-order is constituted by metaethical questions - it is questions about the system of ideas. The prolongation of this distinction is a division for internal skepticism (first order) and external skepticism (second order). The former must assume the truth of certain general moral claims "They rely on morality to denigrate morality" $(2011,31)^{35}$ while the latter assumes Archimedean point — the external perspective- "They are able to denigrate moral truth, they say, without relying on it" $(2011,32) .{ }^{36}$ One of subdivisions is made within external skepticism and it leads to error skepticism and status skepticism. The former consists of value neutrally metaphysics, which eliminates the morality from the categories of our universe. The latter one claims that the ordinary view is not a description but it consists in masked orders-“Cheating is wrong" means in reality "Don't cheat!" Internal skepticism however takes various forms - besides the key examples which are cultural relativism, we can find the internal error skepticism, which Dworkin describes subsequently: "Other people are internal error skeptics about the place of morality in foreign policy. They say that it makes no sense to suppose that a nation's trade policy can be either morally right or wrong. They reject positive moral judgments that many other people hold..." (2011, 33). ${ }^{37}$ Another example of the internal skepticism is global internal skepticism. Only supernatural power could settle down moral claims as true, so our claims cannot be universal and our acts are such irrelevant in the face of universe. The skeptical problem touches in this stage an investigation about determinism and non-detrminism. But what does it mean in the context of social life? Dworkin uses an interesting case from astrology and religion. Every attempt to negate astrology or theism as itself is not astrological or religion assertions, but:

However, if we define an astrological judgment as one that describes the character and extent of planetary influence, then the statement that there is no such influence is indeed an astrological judgment. If we define a religious position as one that presupposes the existence of one or more divine beings, then atheism is not a religious position. But if we define it as one that offers an opinion about the existence or properties of divine beings, then atheism certainly is a religious position. ${ }^{38}$ $(2011,40-41)$

On the social background, it means that every interpretation takes place within a social life context and there does not exist such thing like Archimedean point. Only one version of skepticism makes sense- this is internal skepticism understood as critical approach to the functioning moral concepts.

Another burden which we should remove to reach a level of reflexive argumentation is, what Dworkin calls semantic sting, "There is the sting: we are marked as its target by too crude a picture of what disagreement is or must be like" $(1998,46) .{ }^{39}$ This Oxford jurist sets on contrary to semantic sting, interpretative concepts. These concepts are the subjects of disagreements and require to develop argumentation. They set the common ground for people, who do not agree with each other. The best example of interpretative concepts is concept of justice which is an object of permanent controversy.

Another problem has been signalized by Karl Raymund Popper. It is so-called verbalism. One of the Popper's postulates is the supremacy philosophical problems over language problems like these related to defining. This language vein Popper named verbalism and he tries to argue against it. He says that real development of wisdom could be reached only by identifying and solving philosophical problems: 
Apart from the reference to theories and hypotheses which is likely to be of a much later date, this exhortation cannot be very far from an articulation of the feelings I harboured when I first became conscious of the trap set by worries or quarrels about words and their meanings. This, I still think, is the surest path to intellectual perdition: the abandonment of real problems for the sake of verbal problems. ${ }^{40}(16)$

\subsection{Paradigmatic Argumentation (E)}

This type of argumentation is quite similar to particular audience argumentation, but after crossing the reflexive threshold, there is possibility to change the point of view, using another paradigm. The problem with translation is still on the top, but the change of paradigms could be done with rational or irrational factors. Those conceptions should be recognized as derived from Thomas Kuhns's The Structure of Scientific Revolutions $^{41}$ and with former works of polish philosopher Ludwik Fleck. ${ }^{42}$ We can find similar idea in the Alasdair MacIntyre's theory where he investigates rationalities of traditions. In his researches, he shows that moral reasoning of individuals is strictly related to orientation among many different traditions:

What such an individual has to learn I show to test dialectically the theses proposed to him or her by each competing tradition, while also drawing upon these same theses in order to test dialectically those convictions and responses which he or she has brought to the encounter. Such person has to become involved in the conversation between traditions, learning to use the idiom of each in order to describe and evaluate the other or others by means of it. ${ }^{43}(1988,398)$

It is worth to notice that the essence of tradition is self-reforming. This process is possible only with the measure from other traditions. The problems which are given tradition have to face in face change this tradition.

Argumentation within this type is part of scientific process. We have to know that certain arguments could be marginalized but on the other hand paradigms are still changing and this is essence of scientific approach. Relevant part of this attitude is a truth-direction—strong convenience that we follow the truth. If this is our purpose, we can be sure that this is the way of evolutionary growth of scientific knowledge. ${ }^{44}$ This plot is the main aim of critics from the perspective of relativistic argumentation $(\mathrm{F})$.

\subsection{Relativistic Argumentation (F)}

On our map of argumentation relativistic arguments appear in symmetrical relation with emotivistic argumentation. But the difference is relevant. In the emotivistic arguments, there is no such a thing like rationality or quasi-rationality. In relativistic argumentation, we can find equivalent of rationality. Example of this argumentation in the clearest version is Richard Rorty's final vocabulary and the chief principle of order is irony.

All human beings carry about a set of words which they employ to justify their beliefs, and their lives. These are words in which we formulate praise of our friends and contempt for our enemies, our long-term projects, or deepest self-doubts and our highest hopes. They are the word in which we tell sometimes prospectively a sometimes retrospectively the story of our lives. I shall call these words a person's "final vocabulary.",45 $(1989,73)$

Rorty articulates analogy with emotivistic argument expressing verbis:

This is why I think of imagination and rather than reason (considered as the ability to argue), as the faculties which do the most to make moral progress possible. I do not want to be a neo-Aristotelian, I want to be neo-Humean. There is a big difference. The neo-Humean view is best set forth in a recent book by the American philosopher Anette Baier, Moral Prejudice. Baier urges that we substitute justified trust for obligation as our fundamental moral category. She takes the trust-obligation distinction to epitomize the Kant-Hume distinction. ${ }^{46}(1996,49)$ 
And now we can face certain paradox of relativism, because of prima facie, it is far from enforce moral principles and oughts - it's going toward subjectivism in this point—but in fact it enforces some principles anyway. This principle is relativism as regulatory factor. There are deep conveniences, but they should not be presented in public sphere, and if it would be presented within public sphere, there has to be the chief principle-irony.

Władysław Tatarkiewicz writes on relativism:

Relativism or relativistic theory in the scope of some object we named the theory which the main traits of this group of object adopts a relative or contingent trait. In this sense, common relativism is that which all traits of object see as relative. Ethical relativism or axiological relativism is that which good and evil or, in different words, positive and negative values peoples or things find as relative. ${ }^{47}(1986,79)$

Similarly as in the emotivistical arguments, we can see separation from the category of rationality, but not entirely:

So the notion of rationality that I still find useful does not have much to do with truth. It has more to do with notions like curiosity, persuasion, and tolerance. I think of these moral virtues as the virtues of a rich and secure culture... So I would like to use term "rationality" in the way which does not relate to knowledge and truth, but with political and moral virtues of rich and tolerant societies and audiences of higher level, which are possible in this kind of societies. ${ }^{48}(1996,119)$

When he is writing on audience of higher level, we can see that he leaves the particular audiences, like for example communities of believers where arguments from type $\mathrm{C}$ are obliged. Rorty criticizes universal audience in the following words:

I think the notion of "the force of the better argument," which Apel and Habermas have often used, needs to be supplemented and expanded with the notion of better dictionary or the power of better language. I think that the notions of unconditionality and universal validity run into trouble when you go from one set of truth candidates to another. ${ }^{49}$ (1996, 85)

He added also that the universal auditorium is some kind of heuristic fiction.

To sum up, in the relativistic argumentation approach, we deal with critic of universal audience and constraints of some particular audiences. Jürgen Habermas sheds a new light on this problem:

Rorty set out conditions for context of free and tolerant discussion. Relevant persons, information, and reasons, this form of communication should rule out any kind of exclusionary and repressive mechanisms, propaganda, brainwasching, and so on. In stressing the open, inclusive, nonrepressive features of a communication within a more and more idealized auditorium, Rorty approaches willi-nilli my description of "rational discourse" and Putnam's formula of truth as "rational acceptability under idealized conditions." With this kind of "superassertability," Rorty unintended move back to the so-called "Plato cultures." ${ }^{, 50}(1996,21)$

Let us go through this way to the last type of argumentation which we called logically closed argumentation.

\subsection{Logically Closed Argumentation (G)}

Bases of these arguments are built by dogmatic assumption and the main criterion of truth is its coherence within the system. One of the most adequate examples is Hegelian philosophical system which bases on fundamental speculative figure. Like Herbert Schnadelbach writes:

The basic Hegel's thesis is: If we could within entirety distinguish its parts in this mode that alongside these parts, we shall put separated entirety (Entität), so this separate object is just another part among other parts... But this is exactly reason for which we meet a logical problems, which the best way to demonstrate is show the formula proposed by Hegel for his basic 
speculative figure: "Identity of identity and non-identity... according to Hegel we can reach 'concrete' understanding only if we think about some thong and on its opposite what is identity with this what is not identity." ${ }^{\text {"51 }}(2006,12-14)$

The clue of basic speculative figure is the rejection of the principle of contradiction, what Karl Raymund Popper recognizes as the main reason of dogmatism:

Kant refuted rationalism by saying that it must lead to contradictions. I admit that. But it is clear that argument draws its force from the law of contradiction: It refutes only such systems as accept this law, i.e., such as try to be free from contradictions. It is no dangerous to system like mine which is prepared to put up with contradictions - that is, for a dialectic system. It is clear that this argument establishes a dogmatism of an extremely dangerous kind - a dogmatism which need no longer be afraid of any sort of attack... The main danger of such a confusion of dialectic and logic is, as I said, that it helps people to argue dogmatically. For we find only too often that dialecticians, when logical difficulties, as a last resort, tell their opponents that their criticism is mistaken because it is based on logic of the ordinary type instead of on dialectic, if they would only use dialectic, they would see that the contradictions which they have found in some arguments of the dialecticians are quite legitimate (namely from dialectic point of view) ${ }^{52}(2002,440-1)$

The core of this kind of argumentation is coherence theory of truth. Coherence is the only one condition of true sentence. The biggest problem of this approach is, derived from rejection the correspondence theory of truth, lack of relation with reality. When we "observe" logically closed argumentation from the external perspective, they seem paradoxical. The examples we can find in Novalis's apothegms (operated with licentia poethica) or idealistic epistemology which is criticized by Popper in the following words: ... "How can our minds grasp the world?"- - seem to me not to be at all clearly formulated. And the idealist answer, which has been varied by different idealist philosophers but remains fundamentally the same, namely, "Because the world is mind-like," has only the appearance of an answer. We shall see clearly that it is not a real answer if we only consider some analogous arguments, like: "How can this mirror reflect my face?"-Because it is face-like. Although this sort of argument is obviously utterly unsound, it has been formulated again and again. We find it formulated by Jeans, for instance, in our own time, along lines like these: "How can mathematics grasp the world?"- "because the world is like mathematics-like." He argues that reality is of the very nature of mathematics - that the world is mathematical thought (and therefore ideal). This argument is obviously no sounder than the following: "How can language describe the world?"- "Because the world is language-like"-it is linguistic, and no sounder than: "How can the English language describe the world?"- "Because the world is intrinsically British." ${ }^{, 53}$ Strictly political example is idea of volonte generale (J. J. Rousseau), which assumes act of belief of general will as the source political power.

To sum up, in the section G, deciding factor has relation with basic speculative formula which is the base of system and another important factor is internal coherence. Perfect example of criticism of this kind of argumentation is Isaiah Berlin thesis on determinism. ${ }^{54}$ These are extremely simple remarks. He suggests that in theoretical dimension determinism might be true. But just try to wonder how much we would have to change our moral language and social institution. Category of responsibility should be absolutely removed from the law and political consideration. This world would not be real anymore. And here we meet main (actually biggest we can imagine) deficiency of logically closed argumentation - lack of connection with real world.

\section{Conclusion}

The map of argumentation which has been drawn above shows clearly that there function few types of argumentation. There are no hierarchy orders but certain set of relations. Argumentative potential is just a 
litmus paper which uncovers field of argumentation. This field does not exhaust all types and models of argumentation. But it leads us to claiming that there is a lot kinds of rationality which constitutes arguments and points of view. This map is our first step for analyzing types of rationalities which consist of discovering hidden types of rationality within given points of view or searching relation between them.

\section{Notes}

1. Artur Schopenhauer, The Art of Always Being Right, Gibson Square, 2009.

2. Daniel Dennet, Intuition Pumps and Others Tools for Thinking, Penguin Books, London 2014, 411.

3. Michał Heller, Przeciw fundacjonizmowi (Against Foundationalism), Idem, Filozofia $i$ wszechświat. Wybór pism (Philosophy and the Universe. Chosen Works), Universitas, Kraków, 2006, 95.

4. Karl Raymund Popper, Open Society and Its Enemies, (II volumes), Princeton University Press, Princeton, 1966, 433.

5. We can find the idea of using pros hen as analitical instrument in the context of political philosophy in Łukasz Dominiak's dissertation on communitarianism; Ł. Dominiak, Wartość wspólnoty. O filozofii politycznej komunitaryzmu (The Value of Community), Wydawnictwo Adam Marszałek, Torun 2011, 11, passim.

6. John Dewey, Lectures on Psychological and Political Ethics: 1898, edited by D. F. Koch, Hafner Press, New York, 1976, 61.

7. Ibid., 60.

8. John Dewey, How We Think? D. C. Heath \& CO., Publishers, Boston New York Chicago, 1910, 47.

9. Michał Heller, op. cit., 93.

10. John Finnis, Natural Law and Natural Rights, Oxford University Press, Oxford New York, 2011.

11. Ibid., 68 .

12. Ibid., 69.

13. Aristotle, Metaphysics, 1005a-1005b.

14. Steven Lukes, Liberals and Cannibals. On Implications of Diversity, Verso, London, 2003, 114.

15. John Finnis, Fundamentals of Ethics, Georgetown University Press, Waszyngton, 1983, 4-5.

16. Mikołaj Bierdiajew, Fundamentalna idea filozofii Lwa Szestowa (The Fundamental Idea of the Philosophy of Lev Shestov), [w:] Lew Szestow, Spekulacja i objawienie, Wydawnictwo Marek Derewiecki, Kęty, 2007, 8-9.

17. Lew Szestow, Dostojewski i Nietzsche. Filozofia tragedii (Dostoevsky and Nietzsche the Philosophy of Tragedy), Czytelnik, Warszawa, 1987.

18. Michał Heller, op. cit., 91.

19. Jürgen Habermas, The Future of Human Nature, Polity Press, Cambridge, 2003, 92-94.

20. John Rawls, A Theory of Justice. Revised edition, The Belknap Press of Harvard University Press, USA, 1999, 40-47; Ronald Dworkin, Taking Rights Seriously, Bloomsbury, London New York, 1997, 185-222.

21. Alasdaire MacIntyre, Whose Justice? Which Rationality? University of Notre Dame Press, Notre Dame Indiana, 1988, 305.

22. Lesław Niebrój, Bioetyka programów życiowych. Rozwinięcie koncepcji pryncypializmu Beauchampa $i$ Childressa (Bioethics of Life Projects. Development of Beauchamp and Childress Idea of principlism), Wydawnictwo Tekst, Katowice, 2010, 174.

23. Chaim Perelman, Lucie Olbrechts-Tyteca, The New Rhetoric. A Treatise on Argumentation, University of Notre Dame Press, Notre Dame Indiana, 1969, 13-59.

24. Chaim Perelman, Logika prawnicza. Nowa retoryka (Law Logic. New Rhetoric), Wydawnictwo Naukowe PWN, Warszawa, 1984, 158.

25. Chaim Perelman, Lucie Olbrechts-Tyteca, op. cit., 28-30; 463.

26. Ibid., 31.

27. Ibid., 32 .

28. Ibid., 32 .

29. Ibid., 34 .

30. Ibid., 35 .

31. Ibid., 502.

32. Ibid., 491.

33. Ibid., 31 .

34. Ibid., 483.

35. Ronald Dworkin, Justice for Hedgehogs, Belknap Press, USA, 2011, 31.

36. Ibid., 32 .

37. Ibid., 33 .

38. Ibid., 40-41. 
39. Ibid., Law's Empire, Hart Publishing, Oxford, 1998, 46.

40. Karl Raymund Popper, Uneended Quest. An Intelectual Autobiography, Routledge Classic, 16.

41. Thomas Kuhn, The Structure of Scientific Revolutions, The University of Chicago Press, Chicago London, 1996.

42. Ludwik Fleck, Powstanie i rozwój faktu naukowego. Wprowadzenie do nauki o stylu myślowym i kolektywie myślowym (Genesis and Development of Scientific Fact), Wydawnictwo Lubelskie, Lublin, 1986. 398.

43. Alasdair MacIntyre, Whose Justice? Which Rationality? University of Notre Dame Press, Notre Dame Indiana, 1988,

44. Karl Raymund Popper, Objective Knowledge. An Evolutionary Approach, Oxford University Press, USA, 1972, 32-105; 256-318.

45. Richard Rorty, Contingency, Irony, and Solidarity, Cambridge University Press, USA, 1989, 73.

46. Ibid., "On Moral Obligation, Truth and Common Sense," Debating State of Philosophy: Habermas, Rorty and Kołakowski, edited by J. Niżnik and J. T. Sanders, Praeger Publishers, USA, 1996, 49.

47. Władysław Tatarkiewicz, O filozofii i sztuce (On Philosophy and Art), Polskie Wydawnictwo Naukowe, Warszawa, 1986, 79 .

48. Richard Rorty, The Notion of Rationality [w:] Debating State of Philosophy: Habermas, Rorty and Kolakowski, edited by J. Niżnik and J. T. Sanders, Preaeger Publishers, USA, 1996, 119.

49. Ibid., 85 .

50. Jürgen Habermas, "Coping with Contigencies-The Return of Historicism," Debating State of Philosophy: Habermas, Rorty and Kolakowski, edited by J. Niżnik and J. T. Sanders, Preaeger Publishers, USA, 1996, 21.

51. Herbert Schnadelbach, Hegel. Wprowadzenie (Hegel. Introduction), Oficyna naukowa, Warszawa, 2006, 12-14.

52. Karl Raymund Popper, "What Is Dialectic?" Conjectures and Refutations. The Growth of Scientific Knowledge, Routledge, London New York, 2002, 440-1.

53. Ibid., 443.

54. Isaiah Berlin, Four Essays on Liberty, Oxford University Press, Oxford, 1990. 